\title{
Sociedade da aprendizagem: informação, reflexão e ética
}

\author{
Kelley Gonçalves Dias Gasque \\ Doutoranda e mestre em ciência da informação pela \\ Universidade de Brasília. Especialista em literatura brasileira \\ pela Universidade Católica de Brasília. Assessora do Núcleo de \\ Tecnologia da Informação do Colégio Marista de Brasília. \\ E-mail: Kdias@marista.org.br \\ Ricardo Tescarolo \\ Doutor em Educação pela USP. Professor do Programa de \\ Pós-graduação Stricto Sensu em Educação da PUCPR. \\ E-mail: rtescarolo@marista.org.br
}

\section{Resumo}

Este artigo discute o pensamento reflexivo como fator decisivo na produção do conhecimento. São apresentadas concepções que tratam da natureza da informação e do conhecimento, discutindo-se a aprendizagem como forma de acesso à emergente sociedade, por essa razão denominada 'sociedade da aprendizagem'. Conclui-se que, no contexto atual de profundas transformações, o pensamento reflexivo será efetivo se inspirado na ética, condição fundamental para a emancipação humana.

Palavras-chave

Informação; Conhecimento; Pensamento reflexivo; Ética.

\section{Learning society: information, reflection, and ethics}

\begin{abstract}
This article discusses the reflexive thinking, considered as an effective condition in knowledge production. Some of the concepts presented deal with the nature of information and knowledge, discussing the fundamental participation of learning as a way of access for an emergent society, for this very reason called 'learning society'. The conclusion is that, in the present context of deep transformations, the reflexive thought shall be effective if based on ethics, a fundamental condition for emancipation of mankind.
\end{abstract}

Keywords

Information; Knowledge; Reflexive thinking; Ethics.

\section{INTRODUÇÃO}

Um dos grandes desafios contemporâneos é o enfrentamento da expansã

o descontrolada da informação, o sinal mais evidente da emergência de um tipo de sociedade que parece conjugar a produção de quantidades gigantescas de informação, a utilização intensiva de tecnologias eletrônicas em rede e um intenso processo de aprendizagem permanente.

A articulação dessas características sugere a natureza auto-referente dessa sociedade, em que aprender constitui a ação nuclear. Não é surpreendente, pois, que, a partir da concepção de uma 'sociedade da informação', passouse à de 'sociedade do conhecimento'. A cultura simbólica dessa sociedade implica novas formas de aprendizagem, o que sugere a emergência de um modelo de 'sociedade' cujos veículos mais eficazes de acesso são os "processos de aquisição desse conhecimento, uma vez que são as ferramentas mais poderosas para espalhar ou distribuir socialmente essas novas formas de gestão do conhecimento" e que podemos denominar 'sociedade da aprendizagem' (Pozo, 2004, p. 11-12).

Nessa sociedade, está implícita a idéia da existência de níveis hierárquicos ou estágios progressivos diretamente vinculados ao processo de aprendizagem desse conhecimento. Seria então possível reconhecer quatro estágios dessa progressividade: (1) o dado, (2) a informação, (3) o conhecimento e (4) a inteligência (Urdaneta, 1992 apud Moresi, 2000).

Setzer (2001), estudando os três primeiros estágios dessa progressão, entende que os dados constituem uma seqüência de símbolos quantificados ou quantificáveis com valor sintático; a informação, uma abstração informal significativa que ocorre na mente de alguém e comporta um elemento semântico, podendo ser representada por meio de dados; e o conhecimento, a abstração interior, pessoal, de alguma experiência de vida.

Na mesma linha de argumentação, Polanyi (1962), em sua obra Personal knowledge, entende que é preciso mobilizar certas capacidades e atitudes gerais para o acesso e o manejo da informação e a conseqüente geração do conhecimento, o que ocorre a partir do pressuposto de que há sempre um elemento pessoal essencial como componente estrutural 
de qualquer tipo de conhecimento, que ele denominou 'conhecimento pessoal' e distinguiu tanto do sentido de um conhecimento totalmente subjetivado, quanto daquele totalmente objetivo.

O conhecimento, por sua natureza complexa, pode refletir abordagens diferentes, dependendo da concepção epistemológica que o sustenta. De todo modo, parece haver consenso em relação à natureza dos três primeiros estágios da progressão informacional, cuja perspectiva se inscreve no que denominamos abordagem cognitiva. Conforme tal concepção, o conhecimento só é entendido como tal quando processado por uma estrutura mental a partir de um conhecimento prévio. Dessa forma, a informação representa um elemento exógeno que corresponde à matériaprima a ser transformada em conhecimento por meio da interpretação e compreensão de cada indivíduo.

Corroborando essa idéia, Barreto (2001) afirma que

As configurações, que relacionam a informação com a geração de conhecimento, são as que melhor explicam a sua natureza, em termos finalistas, pois são associadas ao desenvolvimento do indivíduo e a sua liberdade de decidir sozinho. Aqui a informação é qualificada como um instrumento modificador da consciência do homem. A informação, quando adequadamente assimilada, produz conhecimento, modifica o estoque mental de saber do indivíduo e traz benefícios para seu desenvolvimento e para o bem-estar da sociedade em que ele vive.

Tornar a informação disponível, portanto, não é suficiente para que se caracterize a sociedade da aprendizagem, pois "o mais importante é o desencadeamento de um vasto e continuado processo de aprendizagem" (Assmann, 2000, p.9), que depende de um pensamento reflexivo e ético, resultado da mudança na consciência humana que o conhecimento gerado pela informação é capaz de promover.

\section{INFORMAÇÃO, CONHECIMENTO E APRENDIZAGEM}

O conhecimento, mesmo reconhecido como experiência subjetiva, pessoal e intransferível, pode ser exteriorizado como informação para outro ser humano mediante discurso, utilizando símbolos, indícios, sinais, imagens, fala ou escrita. A informação incorporada pelo sujeito humano mediante a aprendizagem se transforma em conhecimento, que não se reduz ao resultado da experiência direta e imediata do sujeito sobre a realidade, nem "a uma fórmula matemática ou à instrução para computador: é arte, conselho, tecnologia, teoria e a motivação que está por trás de toda a comunicação" (Wurman, 1991, p. 361).

Nesse sentido, a informação se identifica como a coisa significada a ser compreendida pelo processo de decodificação e interpretação dos signos que representam os objetos. A eficácia desse complexo sistema de informação e comunicação depende, porém, do desenvolvimento do pensamento reflexivo, capaz de levar o sujeito "à abstração e à construção do sentido” (Gomes, 2000, p.61).

Esse processo - em que informação, conhecimento e seus mecanismos de aquisição se associam simbioticamente - é catalisado pelo sistema educacional, que passou a organizar estruturas especializadas denominadas 'escolas', tendo em conta a demanda para facilitar, aperfeiçoar ou antecipar o processo de aprendizagem e para contribuir para a produção de conhecimento socialmente válido.

A escola passou, então, a sistematizar os processos de seleção e organização curricular do conhecimento, como conteúdo escolar, e a planejar suas diversas atividades pedagógicas, como a mediação didática, a avaliação da aprendizagem e os programas de formação docente. E, para validar-se, promoveu a abertura e a sensibilidade para que fossem identificadas as relações com o seu entorno social, embora sempre criticadas por sua histórica ineficácia.

A ação da escola, assim, encontra sua gênese na transposição didática do conhecimento, processo que o torna passível de ser ensinado, aprendido e avaliado. O conhecimento pedagogicamente transposto articulase com os objetivos e as situações didáticas, que podem favorecer uma aprendizagem significativa, na medida em que for relacionada, "de forma não arbitrária e substantiva, (não literal), uma nova informação a outras”, com as quais a pessoa esteja já familiarizada e na medida em que adotar "uma estratégia correspondente para assim proceder". Contudo, isso não quer dizer que, no caso da aprendizagem significativa, a informação forme "uma espécie de elo simples com os elementos preexistentes da estrutura cognitiva", mas que as formas de obtenção de informação produzem importantes modificações "tanto na nova informação como no aspecto especificamente relevante da estrutura cognitiva com a qual a nova informação estabelece relação" (Ausubel, Novak e Hanesian, 1978, p. 23-48).

Parece haver fortes evidências de que esse conhecimento relacional, advindo da interação sujeito-mundo, depende da história prévia de quem aprende, envolvendo suas experiências, vivências e memórias e, portanto, o significado pessoal e emocional. Contudo, a despeito da subjetividade, o conhecimento científico próprio da aprendizagem reflexiva parece ter algo a expressar que 
lhe é próprio e, portanto, resiste à pura subjetividade do sujeito, por ser freqüentemente fruto de um consenso, nutrido e sustentado pela razão, não se reduzindo, pois, a "uma busca desestruturada de pedaços de informação" ou a um acúmulo de fatos, impressões e opiniões, mas constitui "um processo de teorização a respeito das pessoas e do mundo e que descreve, explica e interpreta os fatos e as coisas, buscando prever o futuro e controlar a natureza" (Moser, Mulder e Trout, 2004, p. 200).

Esse conhecimento busca dar algumas respostas às indagações humanas, tornando-se condição necessária para o bem-estar, desenvolvimento e progresso da humanidade. De acordo com Castells (1999, p. 50-51), "a aplicação desses conhecimentos e dessa informação para a geração de conhecimentos e de dispositivos de processamento/comunicação da informação em um ciclo de realimentação cumulativo entre a inovação e seu uso" é a característica principal da revolução tecnológica do mundo contemporâneo. "No novo modo informacional de desenvolvimento", observa o autor, "a fonte de produtividade acha-se na tecnologia de geração de conhecimentos, de processamento da informação e de comunicação de símbolos" (Castells, 1999, p. 35), processo que caracteriza a emergente sociedade da aprendizagem.

Assim, a aprendizagem, pelo seu poder de transformação, tem sido discutida exaustivamente no cotidiano e no ambiente acadêmico, em especial quando o sujeito humano percebeu que não só aprende como pode apropriar-se dos mecanismos envolvidos no complexo processo de aprendizagem e aperfeiçoá-los.

Várias teorias tentam explicar a aprendizagem. O behaviorismo e o campo-Gestalt parecem ser as teorias mais difundidas. Para o behaviorismo, a aprendizagem é um processo de mudança comportamental que resulta da interação do organismo com o meio mediante estímulos adequados. Toda a aprendizagem é condicionada pelos estímulos, entendidos como agentes ambientais que atuam sobre um organismo, fazendo-o emitir uma resposta. Para a teoria de campo-Gestalt, em contrapartida, a aprendizagem está intimamente relacionada com a percepção. É um processo de aquisição ou mudança de insights, de perspectivas ou padrões de pensamento (Bigge, 1977). Segundo essa abordagem, a aprendizagem e o pensamento estão intimamente relacionados, um não ocorrendo sem o outro. $O$ pensamento é, então, interpretado como um processo reflexivo que sempre produz alguma mudança de insight, ainda que pequena.

Pensar, nessa perspectiva, pode significar formar ou combinar no espírito pensamentos ou idéias; fazer reflexões; discernir; raciocinar, meditar, cismar; tencionar, cogitar; estar preocupado; ter cuidado; avaliar pelo raciocínio; julgar, imaginar; delinear mentalmente; meditar. Pensar pode ainda abranger a recordação, as fantasias, os sonhos, o animismo e as atividades de criação.

Concordando com a perspectiva epistemológica genética de Jean Piaget (Bordenave e Pereira, 1988, p. 28), entendemos que pensar constitui "a base em que se assenta a aprendizagem”. Nesse caso, constitui uma ação individual dirigida e orientada para um fim: a solução de problemas simples ou complexos. $\mathrm{O}$ primeiro tipo de problema não exige deliberações profundas. Assim, o nível de tensão permanece relativamente baixo. Já no segundo caso, encontramos problemas que não são tão fáceis de resolver. Exige-se mais esforço e mais tempo. O nível de tensão, então, é relativamente alto, e, apesar de muitos elementos dos problemas serem familiares, alguns aspectos do problema são imprevisíveis, inéditos ou inesperados, o que requer um alto grau de originalidade ou criatividade (Bigge, 1977).

Os diferentes níveis de aprendizagem, portanto, estão relacionados com diferentes níveis de reflexão, e, quanto maior a capacidade de refletir, mais significativo e mais aprofundado será o pensar empregado na elaboração do conhecimento.

\section{O PENSAMENTO REFLEXIVO E A ÉTICA NECESSÁRIA}

O pensar reflexivo pode ser entendido como um tipo específico de pensar, de natureza ética, cuja função essencial é a de "explicar, esclarecer ou investigar uma determinada realidade, elaborando os conceitos correspondentes" (Sánchez Vázquez, 1998, p. 10), diferente, portanto, dos processos caóticos e desordenados que nos passam pela cabeça.

Segundo Dewey (1979, p. 22), a reflexão é uma forma de pensar que abrange

(1) um estado de dúvida, hesitação, perplexidade, dificuldade mental, o qual origina o ato de pensar; (2) um ato de pesquisa, procura, inquirição, para encontrar material que resolva a dúvida, assente e esclareça a perplexidade.

Consideramos que o pensamento reflexivo se vincula eticamente à ação e requer o exercício das seguintes capacidades:

1- empírica, que permite elaborar um diagnóstico para reconhecer, definir e delimitar um problema, abrangendo as atividades de compilar dados, descrever situações, 
processos, causas e efeitos a partir de dados objetivos e subjetivos;

2- estratégica, relacionada ao planejamento da ação, capaz de prever o que é necessário para atingir os objetivos, descrevendo o porquê, para que, os meios, a forma e o tempo necessário para obtenção dos objetivos;

3- analítica, que busca e seleciona os dados e as informações necessárias para analisar e, a partir deles, construir uma teoria;

4- avaliativa, que diz respeito ao processo de valoração ou emissão de juízo sobre o processo de reflexão e construção do conhecimento;

5- prática, relacionada à análise, à experiência, aos fins e meios para obter um resultado satisfatório;

6- comunicativa, vinculada à forma de comunicar e partilhar as idéias com os pares e com o público em geral (Pollard e Tann, 1987 apud Vasconcelos, 2000).

Contudo, todas as capacidades até aqui relacionadas, embora necessárias, não são suficientes para a compreensão da realidade. Dewey (1979, p.19), avançando nessa idéia, coloca a reflexão como a capacidade que, congregando todas as outras, promove "o exame ativo, persistente e cuidadoso de todas as crenças ou supostas formas de conhecimento, à luz dos fundamentos que as sustentam e das conclusões para que tendem". A reflexão é conseqüência de "uma ordem de tal modo consecutiva que cada idéia engendra a seguinte como seu efeito natural e, ao mesmo tempo, apóia-se na antecessora ou a esta se refere".

Cumpre destacar que, como todo conhecimento envolve riscos, mesmo no campo da ciência, reconhece-se hoje que não há mais certeza ou objetividade absolutas nem verdades estáveis, sugerindo a emergência de um novo paradigma que lança suspeitas sobre a validade de um tipo de 'objetivismo' abalado pelas evidências de um mundo impregnado de valor, e a

beleza racional que a ciência descobre na estrutura do universo e a sensação de maravilha gozada pelos cientistas frente a tais descobertas é parte do encontro com o valor (Polkinghorne, 2001, p. 142).

O conhecimento, em razão de sua natureza provisória, significa mais do que suas evidências empíricas oferecem e jamais pode insinuar a certeza que os resultados parecem proporcionar. E, por mais revolucionário que seja, uma idéia nova deverá conter a anterior, que, por sua vez, será uma aproximação de uma nova idéia. A reflexão é a capacidade humana capaz de promover o discernimento necessário do conhecimento, apoiando-se em argumentos e conclusões próprias e compreendendo:

- uma atitude de dúvida e perplexidade diante de uma situação cuja natureza real ainda não está determinada;

- a tentativa inicial de interpretar as informações disponíveis com potencial para produzir determinadas conseqüências;

- o levantamento meticuloso, com o exame, a exploração e a análise das condições e circunstâncias que possibilitem delimitar e esclarecer o problema;

- a elaboração de uma hipótese a mais consistente e precisa possível, de modo a abranger a maior quantidade de fatos relativos ao problema;

- a tomada de decisão em relação à hipótese proposta e sua testagem e comprovação de eficácia (Dewey, 2001).

Essas condições básicas para o pensamento reflexivo permitem que se apreenda o significado das relações complexas dos acontecimentos e objetos como relações dinâmicas e flexíveis que se costuram e se articulam em teias entretecidas social e individualmente (Machado, 1995).

Nesse contexto, o pensamento reflexivo constitui, segundo o pensamento de Husserl (1996), a faculdade reflexiva da consciência de se voltar para si mesma e de se apropriar de si própria como algo que tem sua própria consistência e seu próprio valor, bem como a percepção que cada pessoa tem de si própria e do mundo, constituindo-se no modo como cada um de nós se relaciona com o mundo exterior, mediada pelos sentidos e pelo corpo, não sendo coisa nem substância, mas função e forma.

É preciso, então, conhecer-se e saber que se sabe, ações que constituem a essência da ética, que, por sua função reflexiva, interpreta, perscruta, compara, pondera e integra a razão com sensibilidade e equilíbrio. Como autoapropriação, torna-nos aptos às mais diversas as atividades do espírito humano, como "abstração, lógica, opções e invenções ponderadas, matemáticas, arte, percepção calculada do espaço e da duração, ansiedades e sonhos de amor" (Chardin, 1986, p. 186).

A experiência humana, assim refletida, ultrapassa as fronteiras do raciocínio lógico formal para explorar o território misterioso do sentido da existência e elaborar a história e o mundo como sistemas em que podemos iniciar nossos próprios processos e empreender nossa ação, o que acaba por constituir uma mediação para a nossa liberdade 
de escolha - o nosso livre-arbítrio - , que constitui a principal forma da expressão da nossa identidade. E a mera suposição de "anulação dessa faculdade comporta idiotice", pois, "sem um espelho delicado e secreto do que passou pelas almas, a história universal é tempo perdido, e nela nossa história pessoal — o que incomodamente nos torna fantasmas" (Borges,1997, p.27).

A reflexão, tendo por base o conhecimento para investigar, explicitar e questionar os conteúdos sociais e culturais, seus pressupostos e fundamentos (Castoriadis, 1999), precisa se alimentar da inquietação da pesquisa, da disposição para o diálogo, do equilíbrio no juízo e da noção da complexidade da realidade, sempre incentivada pela dúvida e pelo espírito crítico (Bobbio, 1977). Por outro lado, não pode deixar de levar em conta permanentemente uma realidade cotidiana impregnada de crenças e expectativas, assim como os critérios de julgamento e a realidade social e política (Nóvoa, 1992).

A ética passa, então, a assumir um sentido mais radical: como responsabilidade a priori e a posteriori em relação às conseqüências de todas as ações humanas. Essa ética interpessoal constitui-se no encontro do conhecimento com a reflexão que pode contribuir decisivamente para a emancipação humana.

\section{CONCLUSÃO}

As discussões propostas neste trabalho nos permitem concluir, embora provisoriamente, que a geração do conhecimento na sociedade da aprendizagem não pode ocorrer, a não ser que seja conduzida por meio do pensamento reflexivo (Ortega E Gasset, 1973), que lhes permita enfrentar suas próprias contradições e desarmar algumas armadilhas grosseiras a que se vê freqüentemente submetido, como o adiamento de tomada de consciência dos problemas que hoje atingem a humanidade e as justificativas e movimentos evasivos para não enfrentá-los.

O pensamento reflexivo, entretanto, só é efetivo se fundado na ética, parâmetro imprescindível para o juízo crítico das nossas ações em sociedade, que adota como pressupostos os valores que propiciam "o diálogo de cada pessoa com a sua própria consciência e com as consciências das outras pessoas, despertando-as de uma eventual indiferença em relação à agressão à vida e à dignidade do outro" (Tescarolo, 2005, p. 140).

No contexto atual de perplexidades, o pensamento reflexivo corresponde à sabedoria prática, proposta por Aristóteles como a virtude intelectual da prudência —phronèsis —, que propicia a dimensão ética da ação, como pode designar, tomando a figura mitológica da divindade grega como referência, uma métis em ação. Esse tipo especial de inteligência, também denominada 'prudência refletida', representa a "perspicácia e sagacidade, antecipação e senso de oportunidade" e se aplica "a campos muito diversos onde a eficiência prática e o sucesso são procurados", estando presente "no devir e na ação" e atuando permanentemente "no campo do dúbio e do equívoco" de modo a poder se adaptar "à simultaneidade e à imprevisibilidade das situações", tão freqüentes no enfrentamento cotidiano (Gauthier et alii,1998, p. 361-362).

E será essa sabedoria prática, ou prudência refletida (métis), que definirá os encontros humanos e transformará a realidade mediante uma ação que considere todas as tensões que, por sua vez, repercutem as confusas relações entre as pessoas. Como senso crítico, a sabedoria prática coordena e questiona a coerência da ação de cada um de nós em relação à responsabilidade pelas conseqüências de nossas intenções e ações, que desse modo assumem uma forma de valor e integram uma determinada ética, da qual forçosamente devem se valer como guia.

Nesse sentido, não é o conhecimento que nos compromete, mas o conhecimento do conhecimento, entendido como a ética que permitirá aperfeiçoar o pensamento reflexivo como instrumento de emancipação humana, até porque é a ignorância dessa condição que deflagra a maior parte dos problemas do mundo (Maturana e Varela, 1995).

Artigo recebido em 14-10-2004 e aceito para publicação em 29-03-2005.

\section{REFERÊNCIAS}

ASSMANN, Hugo. A Metamorfose do aprender na sociedade da informação. Ciência da informação, Brasília, v. 29, n. 2, p. 7-15, maio/ ago. 2000.

AUSUBEL, David P.; NOVAK, Joseph D.; HANESIAN, Helen. Psicologia educacional. Rio de Janeiro : Interamericana, 1978.

BARRETO. Aldo de Albuquerque. A informação em seus momentos de passagem. DataGramaZero, Rio de Janeiro, v. 2, n. 4, ago. 2001. Disponível em: <http://www.dgz.org.br/ago01/Art_01.htm>. Acesso em: 29 nov. 2003.

BIGGE, Morris L. Teorias da aprendizagem para professores. São Paulo : EPU, 1977.

BOBBIO, Norberto. Política e cultura. 2. ed. Turim : Einaudi, 1977.

BORDENAVE, Juan Diaz; PEREIRA, Adair Martins. Estratégias de ensinoaprendizagem. 10. ed. Petrópolis : Vozes, 1988.

BORGES, Jorge Luis. História da eternidade. 4. ed. Tradução de Carmen Cirne Lima. São Paulo : Globo, 1997. 


\section{Kelley Gonçalves Dias Gasque / Ricardo Tescarolo}

CASTELLS, Manuel. A sociedade em red. A era da informação: economia, sociedade e cultura. Tradução de Roneide Venâncio Majer. São Paulo : Paz e Terra, 1999. v. 1.

CASTORIADIS, Cornelius. Feito e a ser feito: as encruzilhadas do labirinto V. Tradução de Lílian do Valle. Rio de Janeiro : DPeA, 1999.

CHARDIN, Teilhard de. O fenômeno humano. São Paulo : Cultrix, 1986.

DEWEY, John. Como pensamos: como se relaciona o pensamento reflexivo com o processo educativo: uma reexposição. 4. ed. Tradução e notas de Haydée Camargo Campos. São Paulo : Nacional, 1979.

Democracia y educación. 4 ed. Madrid : Morata, 2001. (Raíces de la memória).

GAUTIER, Clermont et al. Por uma teoria da pedagogia. Ijuí : UNIJUí, 1998.

GOMES, Henriette Ferreira. O ambiente informacional e suas tecnologias na construção dos sentidos e significados. Ciência da Informação, Brasília, v. 29, n. 1, p. 61-70, jan./abr. 2000.

HUSSERL, Edmund. Investigações lógicas: sexta investigação - elementos de uma elucidação fenomenológica do conhecimento. São Paulo : Nova Cultura, 1996. (Os pensadores)

MACHADO, Nilson José. Epistemologia e didática: as concepções do conhecimento e inteligência e a prática docente. São Paulo : Cortez, 1995.

MATURANA, Humberto R.; VARELA, Francisco G. A árvore do conhecimento. Campinas : Psy, 1995.

MORESI, Eduardo. Delineando o valor do sistema de informação de uma organização. Ciência da Informação, v. 29, n. 1, p. 14-27, jan./abr. 2000.
Moser, Paul K.; Mulder, Dwayne H.; Trout, J. D. A teoria do conhecimento: uma introdução temática. São Paulo : Martins Fontes, 2004.

NÓVOA, A. Os professores e a sua formação. Lisboa : Dom Quixote, 1992.

ORTEGA Y GASSET, José. O homem e a gente. Tradução de J. Carlos Lisboa. Rio de Janeiro : Ibero-Americano, 1973.

POLANYI, Michael. Personal knowledge: towards a post-critical philosophy. Chicago : University of Chicago, 1962.

POLKINGHORNE. Além da ciência: o contexto humano mais amplo. Tradução de Jussara Di Lolli. Bauru, SP : EDUSC, 2001.

POZO, Juán. Aquisição de conhecimento: quando a carne se faz verbo. Tradução de Antonio Feltrin. Porto Alegre : Artmed, 2004.

SÁNCHEZ VÁZQUEZ, Adolfo. Ética. 8. ed. Tradução de João Dell'anna. Rio de Janeiro : Civilização Brasileira, 1998.

SETZER, Valdemar W. Dado, informação, conhecimento e competência. São Paulo : Universidade de São Paulo, Departamento de Ciência da Computação. Disponível em: <www.ime.usp.br/ vwsetzer/dado-info. html>. Acesso em: 22 ago. 2004.

TESCAROLO, Ricardo. Os sistemas complexos e a escola: a ação, o poder e o sagrado. São Paulo : Escrituras, 2005.

VASCONCELOS, Cláudia Cristina. Reflexão: um elemento estruturador da formação de Professores. Millenium, n. 17, 2000. Disponível em:< www. ipv.pt/millenium/17_ect9.htm >. Acesso em: 22 ago. 2004.

WURMAN, Richard Saul. Ansiedade de informação: como transformar informação em compreensão. São Paulo : Cultura, 1991. 